\title{
The joint associations of smoking and obesity with subsequent short and long sickness absence: a five year follow-up study with register-linkage
}

\author{
Eira Roos ${ }^{1 *}$, Tea Lallukka ${ }^{1,2}$, Eero Lahelma ${ }^{1}$ and Ossi Rahkonen
}

\begin{abstract}
Background: Both smoking and obesity are separately associated with sickness absence. Unhealthy lifestyle habits and health conditions may occur concurrently yet studies focusing on their joint association are few. This study examined the joint associations of smoking and obesity with sickness absence (SA).

Methods: A mail survey among employees of the City of Helsinki, Finland, during 2000-2002 included data on obesity, smoking and covariates ( $N=8960$, response rate $67 \%, 80 \%$ women). These data were prospectively linked with register data on self- (1-3 days) and medically certified (4 days or longer) SA among those consenting to the linkage $(n=6986)$. Pregnant, underweight and those with missing data on key variables were excluded $(n=138)$. The total number of participants included in the analyses was 6847. The follow-up time was 5 years. Poisson regression was used to calculate rate ratios (RR).

Results: Among women and men smoking and obesity were associated with self-certified SA. Among women there was a joint association with self-certified SA (obese smokers RR 1.81,95\% Cl 1.59-2.07).

Among women and men smoking and obesity were jointly associated with medically certified SA (for obese smoking women RR 2.23, 95\% Cl 1.93-2.57, for obese smoking men RR 2.69, 95\% Cl 2.03-3.55). Associations remained after adjustments for socioeconomic position, working conditions, health behaviours and self-rated health.
\end{abstract}

Conclusion: Both smoking and obesity are jointly associated with all lengths of sickness absence. Support measures for smoking cessation and prevention of obesity could likely to reduce SA.

Keywords: Absenteeism, Cohort, Epidemiology, Life-style, Middle aged, Mid-life, Work disability

\section{Background}

Health conditions and health behaviours, but also working conditions, socio-economic position and gender all influence sickness absence $[1,2]$.

Regarding health conditions and health behaviours, smoking and obesity are often regarded as some of the strongest risk factors for sickness absence [3-8]. In a Finnish study among municipal kitchen workers both obesity and smoking predicted future sickness absence due to musculoskeletal pain [3]. A similar result was

\footnotetext{
* Correspondence: eira.roos@fimnet.fi

${ }^{1}$ Department of Public Health, University of Helsinki, Post Box 20, 00014 Helsinki, Finland

Full list of author information is available at the end of the article
}

gained in another Finnish study among municipal employees regarding sickness absence due to any cause [4]. Also an Italian study found that obesity and smoking were associated with later sickness absence [5]. Smoking and obesity have been identified as risk factors for sickness absence also in a Danish study among female health care workers [6], in a Dutch study among construction workers [7] and in an American study among 3790 employees [8]. Despite the abundance of studies uncertainties still remain as some of these studies have examined sickness absence due to specific symptoms only [3] or among specific occupations $[3,6,7]$. As sickness absence is strongly associated with socio-economic 
position $[9,10]$ these studies do not necessarily allow generalization to general work force.

It is possible that risk factors such as obesity and smoking bundle together [11], nevertheless we lack studies focusing on the joint association of smoking and obesity with sickness absence. Our recent study showed that there is a joint association of smoking and obesity with premature death, such that obesity intensifies the effect of smoking on mortality risk [12]. If such an effect were present also for sickness absence, it would imply that work disability prevention measures should be targeted to counteract the increased risk of sickness absence among obese smokers in order to enhance their well-being and work ability.

Most of the previous research on sickness absence has assessed the risk of long term sickness absence as it denotes serious health problems and the risk of disability retirement, while short sickness absence spells, especially self-certified, have been much less studied [4]. The reasons behind this are perhaps the lack of reliable data for self-certified sickness absence but also a common misconception that short sickness absence is insignificant as it is typically associated with seasonal flus, common colds and gastroenteritis, i.e. conditions that anyone is prone to catch. However, short sickness absence, may denote the first signs of emerging health problems and work disability [13] and lead to longer sickness absence spells [14]. In clinical practice the high rates of short sickness absence are commonly seen among heavy users of health services. In addition, the recent economic turmoil in Europe has pressured employers to streamline work procedures to high efficacy, meaning that even short sickness absence spells can cause major problems in work community and organization.

The aim of this study was to examine the joint associations of smoking and obesity with short selfcertified and longer, medically certified sickness absence in a multi-occupational employee cohort, taking into account the contribution of covariates that have been shown to associate with smoking, obesity and sickness absence.

\section{Methods}

This study is part of the ongoing Helsinki Health Study on midlife employees of the City of Helsinki, Finland. Baseline mail questionnaire surveys were conducted among all employees turning 40, 45, 50, 55 and 60 years during years 2000-2002 $(n=8960$, response rate $67 \%$, $80 \%$ women) [15]. The survey included questions on health, health behaviours, weight, height, working conditions and sociodemographics. Non-response analyses have shown that the data represent the target population satisfactorily although men, manual workers and younger employees were somewhat underrepresented among the respondents $[15,16]$. The respondents represent several hundreds of different manual and non-manual occupations.

The survey data were linked prospectively with employer's register-based sickness absence data for those that gave consent to such linkage (78\%). Analyses of non-consenting have shown that the consenters represent the target population satisfactorily [16].

\section{Variables \\ Independent variables}

The baseline questionnaire included questions on current smoking. Cigarette, cigar and pipe smoking was asked and $99 \%$ of the smokers were cigarette smokers. According to the responses, smoking was categorized into non-smokers and current smokers. A small number of people with missing data on smoking were excluded $(n=46)$ from the analyses.

Self-reported weight and height were derived from the baseline questionnaire and body mass index (BMI) was calculated according to the standard formula, i.e. weight in kilograms divided by squared height in meters. Weight was categorized as non-obese or obese, using BMI $30\left(\mathrm{~kg} / \mathrm{m}^{2}\right)$ as a cut-off value. Underweight $(\mathrm{BMI}<$ $\left.18.5 \mathrm{~kg} / \mathrm{m}^{2}\right)$ respondents $(n=22)$, pregnant respondents $(n=14)$ and those with missing data on weight or height $(n=56)$ were excluded. Underweight respondents were excluded as though it is known that their risk for sickness absence is heightened $[6,17]$. Their small number made reliable analyses of their risk for sickness absence not feasible. Total number included in the analyses was 6847. Flow chart of the study population is presented in the Fig. 1.

The joint variable of smoking and weight was then formed by cross-tabulating smoking and obesity yielding four categories: non-obese non-smokers, non-obese

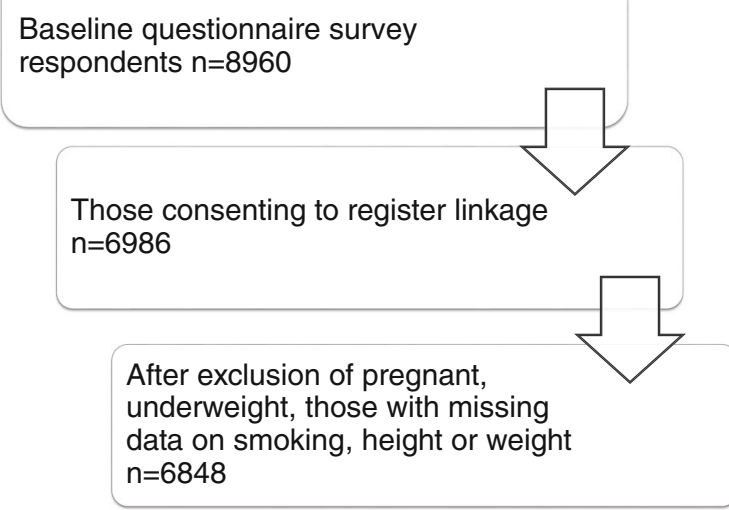

Fig. 1 Flow chart of the study population 
smokers, obese non-smokers, and obese smokers. Nonobese non-smokers were used as the reference category in the analyses.

\section{The dependent variables}

The outcome of the study was the number of sickness absence spells during the five-year follow up after responding to the baseline questionnaire. Data on sickness absence spells were based on the employer's personnel register. These registers are based on employees' salaries and can thus be considered accurate. Sickness absence spells were divided into short selfcertified (1-3 days) and long (4+ days) medically certified sickness absence spells. The employees of the City of Helsinki can take self-certified sickness absence lasting 1-3 days and after three days absence medical certification is required.

\section{Covariates}

Covariates were age, socio-economic position, working conditions, alcohol consumption, leisure-time physical activity and self-rated health. Covariates were chosen as previous studies have shown that they are associated with determinants and the outcome of the study [18-23]. Covariates were obtained from the baseline questionnaire, except for occupational class, which was obtained from personnel register.

Age was treated as a continuous variable. Occupational classes were manual workers, routine non-manual employees, semi-professionals or managers and professionals. Managers and professionals were considered as a reference group as their risk for sickness absence is typically lowest [24]. Working conditions included work arrangements, physical working conditions, and psychosocial working conditions. Work arrangements were encoded as a dichotomous covariate: employees doing regular daytime work formed one group, and the rest formed another group. Regular daytime work was considered as a reference group. Physical working conditions were assessed with an 18-item questionnaire developed at the Finnish Institute of Occupational Health [25]. Factor analyses of the questionnaire provided the following factors: (i) physical workload, such as uncomfortable postures, or heavy physical exertion; (ii) hazardous exposures, such as dirt, solvents, or mold; and (iii) computer work, including sedentary work. Each factor score was divided into quartiles and the lowest quartiles were used as reference groups. Karasek's job content questionnaire was used to measure psychosocial working factors [26]. Separate summary scores for job demands (9 items) and job control (9 items) were divided into quartiles and the lowest quartiles served as reference groups. Alcohol consumption was asked as weekly consumption of spirits, wine and beer and each unit was converted to $12 \mathrm{~g}$ units of pure alcohol. The consumption was divided into quartiles. The lowest quartile was used as a reference group as heavy alcohol use is associated with sickness absence [21]. Leisure time physical activity was measured as average weekly hours of leisure-time physical activity and converted to metabolic equivalent (MET) hours [27] according to the reported intensity. The MET-hours were then divided into quartiles and the highest quartile was used as a reference group as high exercise levels are associated with less sickness absence [22]. Self-rated health was assessed with a single question derived from the Short Form 36 Health questionnaire (SF-36) [28]. Good health was used as a reference group as poor self-rated health is as a strong and independent predictor of work disability [23] and mortality $[29,30]$.

\section{Statistical methods}

First, the number of sickness absence spells and the amount of sickness absence days per hundred person years were calculated. Next, Poisson regression models were used to examine the joint association of smoking and obesity with short and long sickness absence. Men and women were analysed separately as statistically significant interaction $(p$-value $=0.0005)$ was observed between gender and the joint obesity and smoking variable in relation to sickness absence. Four different models were analysed. First model was adjusted for age, the second one was additionally adjusted for occupational class and working conditions. The third model was adjusted for age, alcohol consumption and leisuretime physical activity and the last model was adjusted for age and self-rated health. As adjustments had but a marginal effect on the results, only the first model (Model 1) adjusting for age and the full model (Model 2) adjusting for all covariates are shown.

SAS 9.3 was used in the analyses of the data.

\section{Ethical considerations}

The Helsinki Health Study protocol has been approved by the ethics committees of the Department of Public Health, University of Helsinki, Finland and the City of Helsinki Health Authorities.

\section{Results}

Table 1 shows the descriptive characteristics of key variables of the study population. Sickness absence spells per hundred person years and sickness absence days per person years by obesity and smoking are shown in the Table 2. Non-obese non-smokers had the lowest amount of short and long sickness absence spells as well as sickness absence days both among women and men.

Poisson regression models (Table 3) showed that among women both smoking (non-obese smokers RR 
Table 1 Key characteristics of the study population at baseline

\begin{tabular}{lll}
\hline Variables & $\begin{array}{l}\text { Women } \\
(n=5388)\end{array}$ & $\begin{array}{l}\text { Men } \\
(n=1459)\end{array}$ \\
\hline Age in years (SD) & $50.2(6.6)$ & $49.3(6.6)$ \\
Body Mass Index, BMI (SD) & $25.5(4.4)$ & $26.5(3.9)$ \\
Smoking & $22 \%$ & $26 \%$ \\
Socio-economic position & & \\
$\quad$ Professionals and managers \% & $28 \%$ & $44 \%$ \\
$\quad$ Semiprofessionals \% & $19 \%$ & $20 \%$ \\
$\quad$ Routine non-manual \% & $42 \%$ & $10 \%$ \\
$\quad$ Manual workers \% & $12 \%$ & $27 \%$ \\
Regular day-time work & $79 \%$ & $70 \%$ \\
Poor self-rated health & $25 \%$ & $28 \%$ \\
MET ${ }^{a}$ hours/week (SD) & $28(22)$ & $33(29)$ \\
Alcohol units/week (SD) & $4.0(5.1)$ & $9.2(10)$ \\
\hline
\end{tabular}

${ }^{a}$ metabolic equivalent value

1.34, 95\% CI 1.26-1.44) and obesity (obese non-smokers RR 1.40, 95\% CI 1.28-1.52) were associated with selfcertified sickness absence. They were also jointly associated with self-certified sickness absence (obese smokers RR 1.79, 95\% CI 1.56-2.04). Among men smoking was strongly associated with self-certified sickness absence (non-obese smokers RR 1.81, 95\% CI 1.55-2.12) whereas the association between obesity and self-certified sickness absence was weaker (obese non-smokers RR $1.28,95 \%$ CI 1.00-1.63). Obesity did not strengthen the association between smoking and self-certified sickness absence (obese smokers RR 1.80, 95\% CI 1.33-2.45). Adjusting for socioeconomic position, working conditions, leisure-time physical activity, alcohol consumption, and self-rated health attenuated the risk only modestly.

When considering medically certified sickness absence among women both smoking (non-obese smokers RR 1.56, 95\% CI 1.44-1.68) and obesity (obese non-smokers RR 1.73, 95\% CI 1.58-1.89) were associated with sickness absence, and again there was also a joint association (obese smokers RR 2.23, 95\% CI 1.93-2.57) (Table 4). Among men both smoking (non-obese smokers RR 1.57, 95\% CI 1.31-1.88) and obesity (obese non-smokers RR $1.71,95 \%$ CI 1.35-2.16) were associated with medically certified sickness absence, and their joint association was particularly strong (obese smokers RR 2.69, 95\% CI 2.03-3.55). Again, adjustments for socioeconomic position, working conditions, leisure-time physical activity, alcohol consumption, and self-rated health attenuated the risk somewhat but it remained.

\section{Discussion}

This study examined the joint association of smoking and obesity with sickness absence, considering both short, self-certified sickness absence and longer, medically certified sickness absence among midlife employees. While both smoking and obesity increased the risk of both self- and medically certified sickness absence, the main finding was that smoking and obesity were jointly associated with sickness absence.

In previous research both smoking and obesity have been identified as separate risk factors for long spells of sickness absence [3-8]. Our results show that among women smoking and obesity are jointly associated, meaning that obese smokers have particularly high risk of both self- and medically certified sickness absence. Among men this joint association appears only when considering medically certified sickness absence, however, the joint association is even stronger than among women, referring to multiplicative effect. It is known that smoking is associated with increased risk of many medical conditions that can cause either temporary or more permanent work disability. Such conditions include musculoskeletal disorders [31], respiratory problems [32] as well as heart diseases [33], all of which are also associated with obesity [34]. The mechanism of this interaction is not known and requires further studies.

Only one previous study, using the same data as the present study has examined short self-certified sickness absence and found that smoking and obesity are separately associated with increased risk of short sickness absence [4]. However, their joint associations with sickness absence was not examined in the previous study. The present study extends these results by showing that among men smoking is more strongly associated with short self-certified sickness absence than obesity whereas among women smoking and obesity are jointly associated

Table 2 Sickness absence spells per one hundred person years (100 py) and sickness absence days per person year by baseline body weight and smoking

\begin{tabular}{|c|c|c|c|c|c|c|c|c|}
\hline & \multicolumn{4}{|c|}{ Women } & \multicolumn{4}{|l|}{ Men } \\
\hline & $\mathrm{N}$ & Short n/100 py & Long n/100 py & days/py & $\mathrm{N}$ & Short n/100py & Long n/100py & days/py \\
\hline Non-obese non-smoking & 3544 & 133 & 66 & 14 & 914 & 72 & 41 & 10 \\
\hline Non-obese smoking & 1059 & 184 & 104 & 23 & 322 & 136 & 63 & 15 \\
\hline Obese non-smoking & 617 & 182 & 117 & 28 & 155 & 89 & 67 & 17 \\
\hline Obese smoking & 168 & 243 & 144 & 32 & 68 & 126 & 110 & 32 \\
\hline All & 5388 & 152 & 82 & 18 & 1459 & 90 & 51 & 13 \\
\hline
\end{tabular}


Table 3 The joint association of smoking and obesity with self-certified sickness absence among women $(n=5388)$ and men $(n=1459)$, showing rate ratios (RR) and their 95\% confidence intervals (95\% Cl)

\begin{tabular}{|c|c|c|c|c|c|c|c|}
\hline & \multirow{2}{*}{$\begin{array}{l}\text { Non-obese } \\
\text { non-smoking } \\
\text { RR }\end{array}$} & \multicolumn{2}{|c|}{ Non-obese smoking } & \multicolumn{2}{|c|}{ Obese non-smoking } & \multicolumn{2}{|c|}{ Obese smoking } \\
\hline & & $\mathrm{RR}$ & $95 \% \mathrm{Cl}$ & RR & $95 \% \mathrm{Cl}$ & RR & $95 \% \mathrm{Cl}$ \\
\hline \multicolumn{8}{|l|}{ Women } \\
\hline Model 1 & 1.00 & 1.34 & $1.26-1.44$ & 1.40 & $1.28-1.52$ & 1.79 & $1.56-2.04$ \\
\hline Model 2 & 1.00 & 1.25 & $1.17-1.33$ & 1.28 & $1.18-1.40$ & 1.58 & $1.39-1.80$ \\
\hline \multicolumn{8}{|l|}{ Men } \\
\hline Model 1 & 1.00 & 1.81 & $1.55-2.12$ & 1.28 & $1.00-1.63$ & 1.80 & $1.33-2.45$ \\
\hline Model 2 & 1.00 & 1.56 & $1.32-1.84$ & 1.09 & $0.86-1.39$ & 1.56 & $1.14-2.12$ \\
\hline
\end{tabular}

Model 1 is adjusted for age

Model 2 is adjusted for age, socio-economic position, working conditions, leisure-time physical activity, alcohol consumption and self-rated health

even with short sickness absence. Short, self-certified sickness absence and long sickness absence denote different health problems in the same spectrum of work disability and thus self-certified sickness absence can be considered as a first marker of possible problems in employee's health or coping [13].

Adjusting for health behaviours, socio-economic position, working conditions and self-rated health attenuated the estimates only modestly. In sensitivity analyses self-rated health had the strongest effect, whereas adjusting for other health behaviours had but negligible effects on the estimates. Self-rated health [23], as well as selfassessments of work disability [34] have been shown to predict later work disability and thus its contribution to our results is expected. Although health behaviours had negligible effects in our study, physical activity or alcohol use are significant risk factors for sickness absence $[21,22]$. Thus our results suggest that obesity and smoking are independent and joint risk factors.

This study did not examine the diagnoses leading to sickness absence. However, it is known that obesity and smoking are associated with many diseases that may lead to various lengths of sickness absence. Such diseases include for example lung conditions such as asthma,
Chronic Obstructive Pulmonary Disease (COPD) and lung cancer, musculoskeletal disorders such as back pain and as well as cardiovascular diseases [33, 35-37]. As the mechanisms that lead to mentioned diseases are assumedly different for smoking and obesity it is plausible that their joint association with these diseases is additive.

Intentional weight loss or quitting smoking was not examined in this study. Therefore conclusions on their associations on the risk of sickness absence cannot be drawn. However, our results suggest that quitting smoking or decreasing relative weight could potentially reduce sickness absence. Changing health behaviours is, however, challenging and often requires support measures from health professionals. It is known that quitting smoking [38] appears to be more successful than weight reduction [39]. In occupational health care context it might be more cost effective to focus on smoking cessation support when both risk factors are present although obesity itself is a strong risk factor of work disability [40].

The strengths of this study include a large multioccupational cohort and register-based data on sickness absence as well as the possibility to include short self-certified sickness absence. It has been previously

Table 4 The joint association of smoking and obesity with medically certified sickness absence among women ( $n=5388)$ and men ( $n=1459)$, showing rate ratios (RR) and their 95\% confidence intervals (95\% Cl)

\begin{tabular}{|c|c|c|c|c|c|c|c|}
\hline & \multirow{2}{*}{$\begin{array}{l}\text { Non-obese } \\
\text { non-smoking } \\
\text { RR }\end{array}$} & \multicolumn{2}{|c|}{ Non-obese smoking } & \multicolumn{2}{|c|}{ Obese non-smoking } & \multicolumn{2}{|c|}{ Obese smoking } \\
\hline & & $\mathrm{RR}$ & $95 \% \mathrm{Cl}$ & RR & $95 \% \mathrm{Cl}$ & RR & $95 \% \mathrm{Cl}$ \\
\hline \multicolumn{8}{|l|}{ Women } \\
\hline Model 1 & 1.00 & 1.56 & $1.44-1.68$ & 1.73 & $1.58-1.89$ & 2.23 & $1.93-2.57$ \\
\hline Model 2 & 1.00 & 1.32 & $1.23-1.41$ & 1.40 & $1.29-1.52$ & 1.71 & $1.50-1.94$ \\
\hline \multicolumn{8}{|l|}{ Men } \\
\hline Model 1 & 1.00 & 1.57 & $1.31-1.88$ & 1.71 & $1.35-2.16$ & 2.69 & $2.03-3.55$ \\
\hline Model 2 & 1.00 & 1.20 & $1.02-1.42$ & 1.24 & $1.00-1.53$ & 1.96 & $1.52-2.52$ \\
\hline
\end{tabular}

Model 1 is adjusted for age

Model 2 is adjusted for age, socio-economic position, working conditions, leisure-time physical activity, alcohol consumption and self-rated health 
reported that participants of this study represent the socioeconomic spectrum satisfactorily, although younger and manual employees were slightly less likely to participate at baseline $[15,16]$. The City of Helsinki is the largest employer in Finland with nearly 40,000 employees, representing hundreds of different occupations in both blueand white-collar jobs. However, it should be noted, that the social security systems and the compensation provided for sickness absence vary from country to country and as these factors influence how prone an employee is to take a sick leave these results are not necessarily generalizable to populations that are under different social security system. The survey data relies on self-reports and although selfreported weight has been shown to correspond well with measured weight [41], there might be reporting bias on smoking and other health behaviours. Sensitivity analyses showed that non-obese smokers gave consent to linkage to sickness absence registers slightly less often $(81 \%)$ than the other groups (83-88\%) which suggests that our results are likely somewhat conservative. According to previously published analyses, those consenting to register linkage represent target population satisfactorily [16]. Due to the small number of cases we were unable to examine separately never-smokers and previous smokers.

\section{Conclusion}

Both smoking and obesity are jointly associated with all lengths of sickness absence. However, to fully understand their joint associations further research is required. Support measures for smoking cessation and prevention of obesity are suggested especially in the occupational health setting.

\section{Abbreviations}

BMI: Body Mass Index; Cl: Confidence interval; MET: Metabolic Equivalent; PY: Person years; RR: Rate ratios; SA: Sickness absence

\section{Acknowledgements}

Not applicable.

\section{Funding}

ER is supported by The Finnish Work Environment Fund and by The Finnish Medical Foundation, TL is supported by the Academy of Finland (Grant \#287488 \& 294,096), Helsinki Health Studyis supported by the Academy of Finland (Grant \#1257362 \& \#1294514), by the Finnish Work Environment Fund, and by the Juho Vainio Foundation.

\section{Availability of data and materials}

The data that support the findings of this study are available from Helsinki Health Study but restrictions apply to the availability of these data, which were used under license for the current study, and so are not publicly available. Data are however available from the authors upon reasonable request and with permission of Helsinki Health Study principal investigator.

\section{Authors' contributions}

All the authors have contributed to the planning of the analysis, commented on the manuscript text, and approved the submission and publication. ER performed the statistical analysis.

\section{Ethics approval and consent to participate}

The Helsinki Health Study protocol has been approved by the ethics committees of the Department of Public Health, University of Helsinki, Finland and the City of Helsinki Health Authorities. Informed consent to participate in the study was obtained from participants.

\section{Consent for publication}

Not applicable.

\section{Competing interests}

The authors declare that they have no competing interests.

\section{Publisher's Note}

Springer Nature remains neutral with regard to jurisdictional claims in published maps and institutional affiliations.

\section{Author details}

${ }^{1}$ Department of Public Health, University of Helsinki, Post Box 20, 00014 Helsinki, Finland. ${ }^{2}$ Finnish Institute of Occupational Health, Helsinki, Finland.

Received: 30 March 2017 Accepted: 14 December 2017

Published online: 28 December 2017

\section{References}

1. Labriola M. Conceptual framework of sickness absence and return to work focusing on both the individual and the contextual level. Work (Reading, Mass ). 2008;30(4):377-87.

2. Kaikkonen R, Rahkonen O, Lallukka T, Lahelma E. Physical and psychosocial working conditions as explanations for occupational class inequalities in self-rated health. European journal of public health. 2009;19(5):458-63.

3. Haukka E, Kaila-Kangas L, Luukkonen R, Takala EP, Viikari-Juntura E, LeinoArjas P. Predictors of sickness absence related to musculoskeletal pain: a two-year follow-up study of workers in municipal kitchens. Scand J Work Environ Health. 2014;40(3):278.

4. Laaksonen M, Piha K, Martikainen P, Rahkonen O, Lahelma E. Health-related behaviours and sickness absence from work. Occup Environ Med. 2009;66(12):840

5. Labriola M, Lund T, Burr H. Prospective study of physical and psychosocial risk factors for sickness absence. Occup Med (Lond). 2006 Oct;56(7):469-74.

6. Quist HG, Thomsen BL, Christensen U, Clausen T, Holtermann A, Bjorner JB, et al. Influence of lifestyle factors on long-term sickness absence among female healthcare workers: a prospective cohort study. BMC Public Health. 2014;14:1084.

7. Alavinia SM, van den Berg TI, van Duivenbooden C, Elders LA, Burdorf A. Impact of work-related factors, lifestyle, and work ability on sickness absence among Dutch construction workers. Scand J Work Environ Health. 2009 Oct:35(5):325-33.

8. Pai C, Mullin J, Payne GM, Love J, O'Connell G, Edington DW. Factors associated with incidental sickness absence among employees in one health care system. Am J Health Promot. 2009;24(1):37.

9. Piha K, Laaksonen M, Martikainen P, Rahkonen O, Lahelma E. Interrelationships between education, occupational class, income and sickness absence. Eur J Pub Health. 2010;20(3):276-80.

10. Sumanen $\mathrm{H}$, Rahkonen $\mathrm{O}$, Lahti J, Pietiläinen $\mathrm{O}$, Lahelma E. Educational differences in sickness absence trends among young employees from 2002 to 2013 in Helsinki, Finland. BMJ Open. 2016;6(5):e008550.

11. Sanchez A, Norman GJ, Sallis JF, Calfas KJ, Rock C, Patrick K. Patterns and correlates of multiple risk behaviors in overweight women. Prev Med. 2008;46(3):196

12. Roos ET, Lallukka T, Lahelma E, Rahkonen O. Joint associations between smoking and obesity as determinants of premature mortality among midlife employees. Eur J Pub Health. 2016:

13. Hultin $\mathrm{H}$, Lindholm C, Malfert M, Möller J. Short-term sick leave and future risk of sickness absence and unemployment - the impact of health status. BMC Public Health. 2012:12:861.

14. Helgesson $M$, Johansson B, Wernroth L, Vingård E. Exposure to different lengths of sick leave and subsequent work absence among young adults. BMC Public Health. 2016;16:51.

15. Lahelma E, Aittomäki A, Laaksonen M, Lallukka T, Martikainen P, Piha K, et al. Cohort profile: the Helsinki health study. Int J Epidemiol. 2013;42(3):722-30. 
16. Laaksonen M, Aittomaki A, Lallukka T, Rahkonen O, Saastamoinen P, Silventoinen $\mathrm{K}$, et al. Register-based study among employees showed small nonparticipation bias in health surveys and check-ups. J Clin Epidemiol. 2008 Sep;61(9):900-6.

17. Ferrie JE, Head J, Shipley MJ, Vahtera J, Marmot MG, Kivimaki MBMI. Obesity, and sickness absence in the Whitehall II study. Obesity (Silver Spring). 2007 Jun;15(6):1554-64.

18. Laaksonen M, Piha K, Rahkonen O, Martikainen P, Lahelma E. Explaining occupational class differences in sickness absence: results from middleaged municipal employees. J Epidemiol Community Health. 2010;64(9):802.

19. Roos E, Lallukka T, Rahkonen O, Lahelma E, Laaksonen M. Working conditions and major weight gain-a prospective cohort study. Arch Environ Occup Health. 2013;68(3):166.

20. Wang L, Lee IM, Manson JE, Buring JE, Sesso HD. Alcohol consumption, weight gain, and risk of becoming overweight in middle-aged and older women. Arch Intern Med. 2010;170(5):453.

21. Salonsalmi A, Laaksonen M, Lahelma E, Rahkonen O. Drinking habits and sickness absence: the contribution of working conditions. Scand J Public Health. 2009;37(8):846.

22. Lahti J, Lahelma E, Rahkonen O. Changes in leisure-time physical activity and subsequent sickness absence: a prospective cohort study among middle-aged employees. Prev Med. 2012;55(6):618.

23. Pietiläinen $\mathrm{O}$, Laaksonen $M$, Rahkonen $\mathrm{O}$, Lahelma E. Self-rated health as a predictor of disability retirement-the contribution of ill-health and working conditions. PLoS One. 2011;6(9):e25004.

24. Toch-Marquardt M, Menvielle G, Eikemo TA, Kulhanova I, Kulik MC, Bopp M, et al. Occupational class inequalities in all-cause and cause-specific mortality among middle-aged men in 14 European populations during the early 2000s. PLoS One. 2014;9(9):e108072.

25. Piirainen $\mathrm{H}$, Hirvonen M, Elo AL. The work and health interview study 2003. Basic report. Helsinki: Finnish institute of Occupational Health. 2003;

26. Karasek R. Job demands, job decision latitude, and mental strain: implications for job redesign. Adm Sci Q. 1979;24:285-308.

27. Ainsworth BE, Haskell WL, Whitt MC, Irvin ML, Swartz AM, Strath SJ, et al. Compendium of physical activities: an update of activity codes and MET intensities. Med Sci Sports Exerc. 2000;32(9):S498.

28. Ware JE. SF-36 health survey: manual and interpretation guide: John E. Ware, Jr. ; with Kristin K. Snow, Mark Kosinski, Barbara Gandek. Boston: The Health Institute, New England Medical Center; 1993.

29. DeSalvo KB, Bloser N, Reynolds K, He J, Muntner P. Mortality prediction with a single general self-rated health question. A meta-analysis. J Gen Intern Med. 2006;21(3):267.

30. Stenholm S, Pentti J, Kawachi I, Westerlund H, Kivimäki M, Vahtera J. Self-rated health in the last 12 years of life compared to matched surviving controls: the health and retirement study. PLoS One. 2014;9(9):e107879.

31. Shiri $R$, Falah-Hassani $K$. The effect of smoking on the risk of sciatica: a meta-analysis. Am J Med. 2016;129(1):64.

32. Forey BA, Thornton AJ, Lee PN. Systematic review with meta-analysis of the epidemiological evidence relating smoking to COPD, chronic bronchitis and emphysema. BMC Pulm Med. 2011;11:36.

33. Bullen C. Impact of tobacco smoking and smoking cessation on cardiovascular risk and disease. Expert Rev Cardiovasc Ther. 2008;6(6):883.

34. Guh DP, Zhang W, Bansback N, Amarsi Z, Birmingham CL, Anis AH. The incidence of co-morbidities related to obesity and overweight: a systematic review and meta-analysis. BMC Public Health. 2009:1-20.

35. Schouteten R. Predicting absenteeism: screening for work ability or burnout. Occup Med (Lond). 2017:67(1):52-57.

36. Sasco AJ, Secretan MB, Straif K. Tobacco smoking and cancer: a brief review of recent epidemiological evidence. Lung Cancer. 2004;45(Suppl 2):S3.

37. Yang $\mathrm{H}, \mathrm{Haldeman} \mathrm{S}$. Behavior-related factors associated with low back pain in the US adult population. Spine (Phila Pa 1976). 2016;

38. Cahill K, Hartmann-Boyce J, Perera R. Incentives for smoking cessation. Cochrane Database Syst Rev. 2015;5:CD004307.

39. Loveman E, Frampton GK, Shepherd J, Picot J, Cooper K, Bryant J, et al. The clinical effectiveness and cost-effectiveness of long-term weight management schemes for adults: a systematic review. Health Technol Assess. 2011;15(2):1.
40. Roos E, Laaksonen M, Rahkonen O, Lahelma E, Lallukka T. Relative weight and disability retirement: a prospective cohort study. Scandinavian journal of work, environment \& health. 2013;39(3):259-67.

41. Korpela K, Roos E, Lallukka T, Rahkonen O, Lahelma E, Laaksonen M. Different measures of body weight as predictors of sickness absence. Scand J Public Health. 2013:41(1):25-31.

\section{Submit your next manuscript to BioMed Central and we will help you at every step:}

- We accept pre-submission inquiries

- Our selector tool helps you to find the most relevant journal

- We provide round the clock customer support

- Convenient online submission

- Thorough peer review

- Inclusion in PubMed and all major indexing services

- Maximum visibility for your research

Submit your manuscript at www.biomedcentral.com/submit

) Biomed Central 